\title{
Occupational Health and Safety in the Trucking Industry - Current Trends and Future Challenges
}

\begin{abstract}
Arto Reiman', Seppo Väyrynen²
Abstract Professional truck drivers face various kinds of challenges during their workday. A high prevalence of workrelated musculoskeletal disorders and high accident rates are associated with the trucking industry. In addition, various different psychosocial stressors affect truck drivers' work ability. Accidents, disorders, and stressors all affect working careers. There is both a constant need for a skilled new workforce, but also a need for prolonging working careers. Some characteristics can be identified on truck drivers' work; the drivers mainly work alone and their work contains static work postures while sitting and physical activities while working outside the cab. While working, the driver often faces opportunities for unethical and unsafe actions to ease the workload. This poses challenges to the occupational health and safety (OHS) management. This article provides a scoping review of the risks and hazards that the professional truck drivers face while working. Both driving and non-driving work activities are covered. Special attention is paid to selected new modes of transportation and a discussion is held on the possible OHS challenges that they may bring along. High capacity transports (HCT) are discussed as an emerging mode of road transportation that enables larger loads to be freighted and intermodal transportations (IMT) are used increase the efficiency of the transportations by combining different transportation modes. However, very little attention is being paid in the current OHS literature on the possible adverse OHS effects concerning the driver.
\end{abstract}

\section{Introduction}

Occupational health and safety (OHS) is an ambiguous concept, that can be associated to various different determinants, depending on the definition. In this article, we use a holistic definition that includes not only the aspects that are traditionally associated to OHS, i.e. occupational hygiene, accidents and injuries, and ergonomics and human factors, but also the concept of well-being at work. All these elements include objective and subjective aspects and can be considered interlinked and partly overlapping to each other (e.g. Schulte and Vainio, 2010).

OHS can be identified and discussed as an asset and as a strategic element, affecting companies' activities and economic performance (Dul et al., 2012; Zweetslot et al., 2013). Improper OHS practices and processes lead to negative consequences like decreased work performance and quality and accidents and incidents. The costs related to these can be substantial, reaching from the employee and employer levels to the society level (Rikhardsson, 2004). Well-being at work on the other hand is often associated to more complex subjective determinants and adverse effects may include aspects such as stress, job dissatisfaction, and non-stable work force.

\subsection{OHS Challenges at Road Transportations}

OHS in road transportations has been studied by various different authors (van der Beek, 2012). Truck drivers have been identified as lone workers who cannot be fully monitored by their employers (Huang et al., 2013). For that reason, they often face opportunities for unethical and unsafe actions to ease and quicken their work. Recently for example Reiman, Väyrynen and Putkonen (2015), Reiman et al. (2018), Murphy et al. (2018) and Anderson, Smith and Byrd (2017) have discussed on OHS challenges related to truck drivers' work outside the cab at short haul (SH) delivery transportations and Chandler et al. (2017) have reached that discussion to long haul (LH) transportations. Research literature covers traditional LH and SH freight transportation modes, however very little attention is given on the new modes of transportation.

In this article, we raise two modes of road transportation as examples that have been given increasingly more attention in the Nordic countries and in Europe. Both of them are associated with higher efficiency and being a step towards more sustainable transportations (Ye, Shen and Berqvist, 2014; Bergqvist and Monios, 2016). Firstly, we raise up High Capacity Transportations (HCT). HCTs - as understood in this context - are performed by longer and heavier high capacity vehicles (or mega trucks) whose weights and/or dimensions are outside the permissions and regulations. The EU standard

\footnotetext{
${ }^{1}$ Arto Reiman $(\bowtie)$

Industrial Engineering and Management, University of Oulu, Oulu, Finland

e-mail: arto.reiman@oulu.fi

${ }^{2}$ Seppo Väyrynen

Industrial Engineering and Management, University of Oulu, Oulu, Finland

email: seppo.vayrynen@oulu.fi
} 
for heavy vehicles is 18.75 metres and 40 tonnes. In Sweden and in Finland, for instance, vehicles that reach the maximum length of 25.25 metres and weigh up to 60 tonnes are in a test use. (Ye, Shen and Bergqvist, 2014; Bergqvist and Monios, 2016; Sundin, 2016). Secondly, in intermodal transportation (IMT) more than two modes of transportation are used to freight transportations. For instance, road transportations may be connected to rail, air or sea transportations to reach higher efficiency. There are some indications that the tendency for severe road crashes rises during the wintertime for HCTs (Sandin 2016), however very little - almost none - research has been conducted about OHS at HCTs and IMTs.

\subsection{Objectives}

Our aim here is to conduct a scoping review (Grant and Booth, 2009) in order to facilitate future discussions related to OHS and well-being at work at driving and non-driving tasks for certain modes of road transportation. Especially we pay attention to discussing these challenges from the point of view of Nordic work environmental conditions and social sustainability. We attempt to build new knowledge that reviews and synthesizes the existing literature on the subject. The objective behind this is to summarize findings and to determine research gaps and targets for empirical research in the future.

\section{Methodology}

\subsection{Analysis Approach}

To conduct our survey, we searched for literature in the following research areas. As search words describing the OHS challenges we used: "occupational safety", "occupational health", "well-being at work", "ergonomics" and "human factors". As search words describing the transportation modes we used: "long haul", "short haul", "high capacity transportation" and "intermodal transportation". Search words were used as search terms to find scientific literature via the database of Scopus, a large abstract and citation database of peer-reviewed literature. As we aimed to focus on current and future trends we concentrated only in research literature that was published within last ten years, i.e. 2009-2018. The search was confined to the documents published in English. Additionally, relevant sources found in the previous studies carried out by the authors and in the reference lists of the existing sources were employed as found appropriate. The relevance of the literature was assessed based on the subject areas, the titles and the abstracts. Finally the articles that were deemed the most important were assessed based on the whole text.

\subsection{Search Results}

As the areas to be covered were diverse in nature, the search involved several independent searches, each of which concentrated on a specific area of interest in this paper. Table 1 describes the search word combinations and quantitative results of the searches.

Table 1 Search word combinations and the amount of documents found. OS=Occupational safety, OH=Occupational health, W$B W=$ Well-Being at Work, $H F=$ Human factors, $L H=$ Long haul, $S H=$ Short haul, $H C T=H i g h$ capacity transportation,

\begin{tabular}{lccccc} 
& & \multicolumn{4}{c}{ IMT=Intermodal transportation } \\
\hline LH & OS & OH & W-BW & HF & Ergonomics \\
\hline SH & 11 & 22 & 0 & 8 & 16 \\
\hline HCT & 2 & 4 & 0 & 2 & 3 \\
\hline IMT & 0 & 0 & 0 & 0 & 0 \\
\hline
\end{tabular}

As the results show, the amount of publications in the fields of OS, OH, W-BW, HF and Ergonomics at road transportations is rather limited. The publications focus on traditional long haul and short haul transportation modes, and no research literature was found concerning the two modes of transportation that are in our interest: HCTs and IMTs. The searches did not produce any results when W-BW was used as a search word. In the latter part of the analyses, we combine the categories OS and $\mathrm{OH}$ as OHS and HF and Ergonomics as HFE. 


\section{Results and Discussion}

\subsection{OHS \& HFE Challenges Related to Drivers Work Tasks}

OHS \& HFE challenges related to truck drivers work tasks at LH and SH transportations are described briefly in Table 2. In general, driving related challenges were emphasised in LH transportations, whereas in SH transportations the challenges varied from driving to different actions that are performed outside the cab, i.e. to loading and unloading tasks at customers' premises and courtyards and to actions performed at home terminals, cargo spaces and other parts of the truck bodies.

Table 2 OHS \& HFE challenges related to driving tasks at LH and SH transportation modes.

\begin{tabular}{|c|c|}
\hline & OHS \& HFE challenges \\
\hline LH & $\begin{array}{ll}\text { - } & \text { Long working hours } \\
\text { - } & \text { Non-compliance with hours-of-service rules } \\
\text { - } & \text { Inadequate sleep duration and quality } \\
\text { - } & \text { Sleep fragmentation and sleepiness } \\
\text { - } & \text { Dietary issues } \\
\text { - } & \text { Bad weather conditions } \\
\text { - } & \text { Heavy traffic and possibilities to road accidents/crashes } \\
\text { - } & \text { Lack of other road users actions } \\
\text { - } & \text { Prolonged sitting and whole body vibration } \\
\text { - } & \text { Uncomfortable driving postures }\end{array}$ \\
\hline $\mathrm{SH}$ & $\begin{array}{l}\text { - } \quad \text { Long working hours } \\
\text { - } \quad \text { Non-compliance with hours-of-service rules } \\
\text { - } \quad \text { Tight delivery schedules } \\
\text { - } \quad \text { Accident risks and ergonomic discomforts related to recurrent } \\
\text { work activities outside the cab } \\
\text { - } \quad \text { Cork environment hazards } \\
\text { - } \quad \text { door environtly changing temperatures - from warm cabs to out- } \\
\text { - } \quad \text { Inadequate and/or insufficient tools and devices }\end{array}$ \\
\hline
\end{tabular}

\subsection{OHS\&HFE Challenges in the Nordic Context}

After identifying the most common OHS\&HFE challenges based on the scientific literature, we categorised the challenges in three groups. The categorisation was formed inductively by identifying possible connections between the challenges. The categories selected were formed by the mode of work (driving or non-driving) and environmental conditions. A simplified categorization is presented in Figure 1.

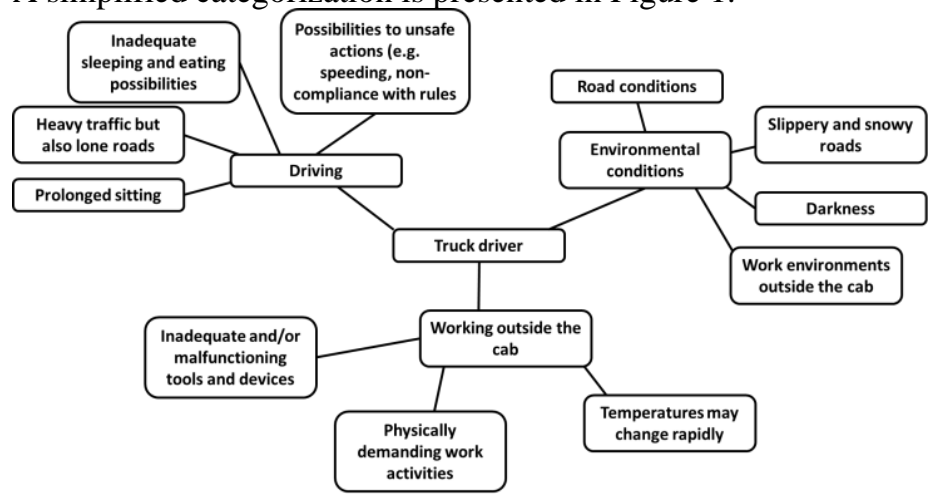

Figure 1 OHS challenges in three categories. 
Environmental conditions cover not only road conditions during driving but also different work environments outside the cab, i.e. the truck body structures and cargo spaces and customers' work premises, courtyards and public places, such as streets. The Driving category illustrates the duality of the driving work. The drivers may face - even during a single work shift - both heavy traffic and lone roads. Driving requires concentration during the whole work shift. Long distances and lone roads may arouse ethical decision making situations; for instance whether or not violate working hours or speed limitations. Long distances are also associated to prolonged sitting. Prolonged sitting combined with whole-body vibration has been identified causing adverse health effects, such as low-back pain.

In addition to driving, truck drivers perform various work tasks outside the cab. In SH transportations these tasks are most often associated to unloading and loading activities at home terminals, cargo spaces and/or at customers' premises. As an opposite of sitting, working outside the cab includes various physical work activities, such as manual materials handling and movements in and out of the cargo space and cab. These are all associated with accidents and incidents in the literature.

Nordic environments bring some specialities to OHS management. For example, the driver may face icy and snowy grounds; from which parts are sanded whilst some parts are left unsanded. This raises possibilities to slipping and falling. In addition, the devices and tools used to ease and fasten the delivery work, such as roll cages, are usually not designed to be used in snow. Temperature changes affect the driver especially at wintertime. The driver constantly changes from warm cabs to outdoor environments; requiring continuous thermoregulatory adjustments.

\subsection{Considerations on Possible OHS\&HFE Challenges at IMTs and HCTs}

As our scoping review reveals, no research has been made on the OHS\&HFE challenges related to IMTs and HCTs. Based on our categorisation above, we emphasise the potential for OHS\&HFE research in IMT and HCT contexts by providing nine new research challenges (see Table 3). We see that there is a need to study drivers' actions during driving. Especial interest should be given to cognitive analyses on driving behaviour and on perceived stress. While working outside the cab we highlight the need to provide more in-depth knowledge on possible new risks that the larger and heavier trucks may bring about and whether any new risks could be identified on the collaboration between different stakeholders while the transportation mode is changed. Further, we highlight the Nordic conditions and social sustainability in general as research topics.

While for instance HCTs and IMTs are considered in general as sustainable transportation solutions, we highlight the social sustainability dimension as a topic for further research in the future. The third dimension of sustainability; social sustainability is often disregarded, while environmental and economic dimensions are paid more attention. Questions such as the drivers' perceptions on the reductions for drivers needed and general road safety perceived by other road users may arouse when social sustainability is discussed.

Table 3 OHS research challenges at IMTs and HCTs.

\begin{tabular}{|c|c|c|}
\hline & IMTs & HCTs \\
\hline Driving & $\begin{array}{l}\text { Perceived stress; } \\
\text { is the driver } \\
\text { aware what s/he is } \\
\text { transporting? } \\
\text { Perceived stress } \\
\text { on load securing }\end{array}$ & $\begin{array}{l}\text { Cognitive and working posture } \\
\text { analyses on driving larger trucks } \\
\text { Perceived stress; does the driver } \\
\text { fear that s/he is causing risk or } \\
\text { discomfort to other road users or } \\
\text { risk to the freight to be damaged }\end{array}$ \\
\hline $\begin{array}{l}\text { Working } \\
\text { outside } \\
\text { the cab }\end{array}$ & $\begin{array}{l}\text { OSH\&HFE risks } \\
\text { during the change } \\
\text { of the transporta- } \\
\text { tion mode }\end{array}$ & $\begin{array}{l}\text { Do larger truck body structures } \\
\text { bring out any new risks for occu- } \\
\text { pational accidents? }\end{array}$ \\
\hline $\begin{array}{l}\text { Nordic } \\
\text { conditions }\end{array}$ & $\begin{array}{l}\text { How are the Nor- } \\
\text { dic special chal- } \\
\text { lenges related to } \\
\text { OHS\&HFE man- } \\
\text { aged at long dis- } \\
\text { tance IMTs? }\end{array}$ & $\begin{array}{l}\text { How does the HCT driver per- } \\
\text { ceive winter conditions at roads? } \\
\text { How do icy and snowy road con- } \\
\text { ditions affect HCT drivers driving } \\
\text { behaviour? }\end{array}$ \\
\hline
\end{tabular}




\section{Conclusions}

Fluent and safe transportations are a basic prerequisite for modern societies. Unsafe trucking can affect at various levels. In addition to road safety in general, unsafe actions while trucking can lead to various kinds of hazards to others as well. The drivers as frontline operators naturally confront different risks for hazards and accidents, but also other people such as by-passers' and other road users' health may be endangered. In addition to human suffering, unsafe actions and accidents give rise to monetary costs reaching from the employer and employee levels all the way to the society level. Thus, a need to improve OHS and HFE at transportations is justified. Truck drivers OHS and HFE challenges were summarized in this scoping review. Especial interest was given to two transportation modes, HCTs and IMTs. Nine new research challenges were identified as future research topics. These research challenges open up a discussion on possible upcoming future OHS and HFE problems. In addition, to reach the discussion outside OHS and HFE attention is paid to the social sustainability dimension.

\section{References}

Anderson, N., Smith, C.K., and Byrd, J.L. (2017), 'Work-related injury factors and safety climate perception in truck drivers', American Journal of Industrial Medicine, 60 (8), pp. 711-723.

Bergqvist, R., and Monios, J. (2016) 'The last mile, inbound logistics and intermodal high capacity transport - the case of Jula in Sweden', World Review of Intermodal Transportation Research, 6(1), pp. 74-92.

Chandler, M.C., Bunn, T.L., and Slavova, S. (2017) 'Narrative and quantitative analyses of workers' compensationcovered injuries in short-haul vs long-haul trucking', International Journal of Injury Control and Safety Promotion, 24 (1), pp. 120-130.

Dul, J., Bruder, R., Buckle, P., Carayon, P., Falzon, P., Marras, W.S., and et al. (2012) 'A strategy for human factors/ergonomics: developing the discipline and profession', Ergonomics, 55 (4), pp. 377-95.

Grant, M., and Booth, A. (2009) 'A typology of reviews: An analysis of 14 review types and associated methodologies', Health Information and Libraries Journal, 26(2), pp. 91-108.

Huang, Y-h., Zohar, D., Robertson, M.M., Garabet, A., Lee, J., and Murphy, L.A. (2013) 'Development and validation of safety climate scales for lone workers using truck drivers as exemplar', Transport Research Part F: Traffic Psychology and Behaviour, 17, pp. 5-19.

Murphy, L.A., Huang, Y-h., Robertson, M.M., Jeffries, S., and Dainoff, M.J. (2018) 'A sociotechnical systems approach to enhance safety climate in the trucking industry: results of an in-depth investigation', Applied Ergonomics, 66, pp. 70-81.

Reiman, A., Väyrynen, S., and Putkonen, A (2015) 'Truck Drivers' Work Systems in Environments Other Than the $\mathrm{Cab}$ - A Macro Ergonomics Development Approach' in Väyrynen, S., Häkkinen, K. \& Niskanen, T. (eds) Integrated Occupational Safety and Health Management - Solutions and Industrial Cases. Cham, SUI: Springer International Publishing, pp. 97-110.

Reiman, A., Forsman, M., Målqvist, I., Parmsund, M., and Lindahl Norberg, A. (2018) 'Risk factors contributing to truck drivers' non-driving occupational accidents', International Journal of Physical Distribution \& Logistics Management, https://doi.org/10.1108/IJPDLM-06-2017-0216.

Rikhardsson, P.M. (2004) 'Accounting for the cost of occupational accidents', Corporate Social Responsibility and Environmental Management, 11(2), pp. 63-70.

Sandin, J. (2016) 'Effects of Higher Capacity Vehicles on traffic safety in Sweden' HVTT14 Future pathways conference, 15-18 November. Rotorua, New Zealand.

Schulte, P., and H. Vainio. (2010) 'Well-being at work - Overview and perspective', Scandinavian Journal of Work Environment and Health, 36 (5), pp. 422-429.

van der Beek, A.J. (2012) 'World at work: truck drivers', Occupational and Environmental Medicine, 69 (4), pp. 291295.

Ye, Y., Shen, J., and Bergqvist, R. (2014) 'High-capacity transport associated with pre- and post-haulage in intermodal road-rail transport', Journal of Transportation Technologies, 4 (3): 289-301.

Zwetsloot, G.I.J.M., Aaltonen, M., Wybo, J-L., Saari, J., Kines, P., and De Beeck, R. (2013) 'The case for research into the zero accident vision', Safety Science, 58 (Oct), pp. 41-48. 